\title{
Distribution and bioavailability of arsenic in natural waters of a mining area studied by ultrafiltration and diffusive gradients in thin
} \section{films}

\author{
Erik S.J. Gontijo a, *, Cláudia H. Watanabe ${ }^{a}$, Adnívia S.C. Monteiro ${ }^{\text {b }}$, Paulo S. Tonello a \\ Gilmare A. da Silva ${ }^{c}$, Kurt Friese ${ }^{\mathrm{d}}$, Hubert M.P. Roeser ${ }^{\mathrm{c}}$, Andre H. Rosa ${ }^{\mathrm{a},{ }^{* *}}$ \\ a Universidade Estadual Paulista Júlio de Mesquita Filho (UNESP), Avenida Três de Março, 511, Alto da Boa Vista, 18087-180, Sorocaba, São Paulo, Brazil \\ ${ }^{\mathrm{b}}$ Universidade Estadual Paulista Júlio de Mesquita Filho (UNESP), Avenida Prof. Francisco Degni, 55, Jardim Quitandinha, 14800-900, Araraquara, São Paulo, \\ Brazil \\ ${ }^{\mathrm{c}}$ Universidade Federal de Ouro Preto (UFOP), Campus Universitário, Morro do Cruzeiro, 35400-000, Ouro Preto, Minas Gerais, Brazil \\ d Helmholtz-Zentrum für Umweltforschung (UFZ), Brückstraße 3a, 39114, Magdeburg, Germany
}

\section{H I G H L I G H T S}

- Fe and Al occurred mainly in the particulate fraction.

- Most of As was labile, bioavailable and in the free fraction.

- Dissolved Fe and Al mainly in colloidal phase was attributed to organic matter.

- Differences between results of ultrafiltration and DGT were pointed out.

- Probably influence of organic matter in the distribution of As.

\section{A R T I C L E I N F O}

\section{Article history:}

Received 15 March 2016

Received in revised form

9 August 2016

Accepted 22 August 2016

Available online 1 September 2016

Handling Editor: Martine Leermakers

\section{Keywords:}

Dissolved organic matter

Metal speciation

Humic substances

Multivariate analysis

Kohonen neural network
G R A P H I C A L A B S T R A C T

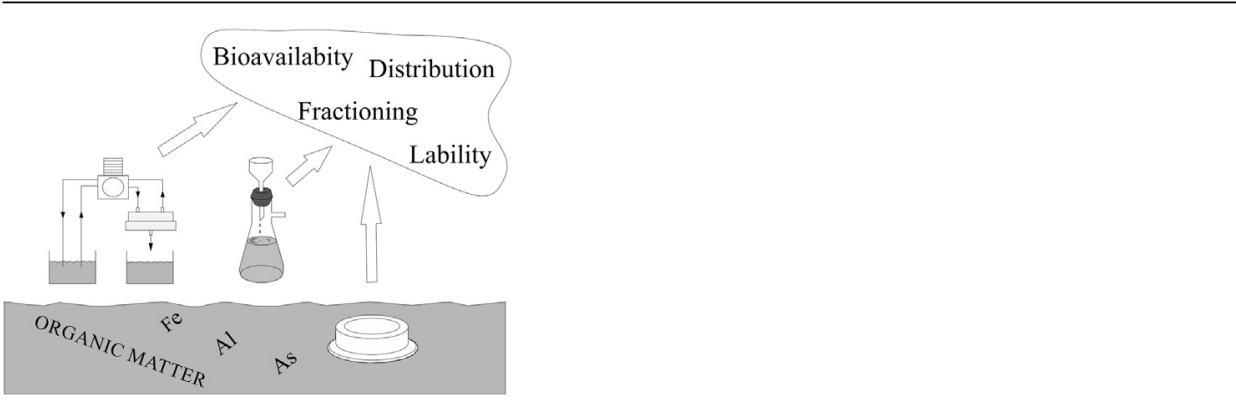

\footnotetext{
* Corresponding author.

** Corresponding author.

E-mail addresses: sartori_jg@hotmail.com (E.S.J. Gontijo), ahrosa@sorocaba. unesp.br (A.H. Rosa).
}

\begin{abstract}
A B S T R A C T
The distribution of metals and metalloids among particulate, dissolved, colloidal, free, and labile forms in natural waters is of great environmental concern since it determines their transportation behaviour and bioavailability. Organic matter can have an important role for this distribution process, since it is an important complexing agent and ubiquitous in the aquatic environment. We studied the distribution, mobility and bioavailability of $\mathrm{Al}$, As and $\mathrm{Fe}$ in natural waters of a mining area (Quadrilátero Ferrífero, Brazil) and the influence of organic matter in these processes. Water samples were taken from 12 points during the dry and rainy seasons, filtrated at $0.45 \mu \mathrm{m}$ and ultrafiltrated $(<1 \mathrm{kDa})$ to separate the particulate, colloidal and free fractions. Diffusive gradients in thin films (DGT) were deployed at 5 sampling points to study the labile part of the elements. Total and dissolved organic carbon and the physicochemical parameters were measured along with the sampling. The results of ultrafiltration (UF) and DGT were compared. The relationship among the variables was studied through multivariate analysis (Kohonen neural network), which showed that the seasonality did not impact most of the samples. Fe and Al occurred mainly in the particulate fraction whereas As appeared more in the free fraction. Most of the dissolved Fe and Al were inert (colloidal form) while As was more labile and bioavailable. The results
\end{abstract}


showed that sampling points with a higher quantity of complexed Fe (colloidal fraction) showed less labile As, which may indicate formation of ternary complexes among organic matter, As and Fe.

\section{Introduction}

The aquatic environment is a complex system where metals and metalloids may exist in different chemical forms. They may be adsorbed in suspended particles, complexed or incorporated with macromolecular ligands, complexed with simple organic or inorganic compounds, adsorbed or assimilated by living organisms or they may occur as free (hydrated) ions (Buffle, 1991; Liu et al., 2013). In addition, these different forms have different behaviours in aquatic systems concerning their bioavailability, mobility and toxicity to living organisms (Forsberg et al., 2006; Tonello et al., 2007). Therefore, the study of such interactions is important in the management of water bodies since it helps to understand the fate of metals and metalloids in the environment, especially the toxic elements (Song et al., 2009).

A way to study the speciation of metals and metalloids in natural waters is the fractionation of their species in waters using different membranes. Based on the size, these fractions can be defined as particulate, colloidal, dissolved, and truly dissolved. The latter fraction can be also defined as a free fraction (FF) although the elements here may appear complexed with small organic or inorganic ligands or as hydrated ions (Forsberg et al., 2006; Tonello et al., 2007). Since toxic elements or metals show different geochemical behaviours in the different fractions, analysis of the total concentration of a metal does not provide information related to its mobility, bioavailability and toxicity. Even the dissolved fraction (DF) does not reveal its real level of contamination, since free ions are considered most toxic (Aung et al., 2008; Lenoble et al., 2015).

Tangential ultrafiltration (TUF) is an example of technique that may be used to characterise metal species of different sizes or molecular weights. The procedure is generally carried out with low pore size membranes (e.g. $1 \mathrm{kDa}$ ) to distinguish the free species from the colloidal ones. In this kind of system, the free species will be determined in the permeate $(<1 \mathrm{kDa})$ and the colloidal species by the difference between dissolved and FF ones $(0.45 \mu \mathrm{m}-1 \mathrm{kDa}$, considering the operational definition used in this work) (Wen et al., 1997; Romão et al., 2003). However, the method has some disadvantages like very long time-consuming filtration step. Moreover, this fact limits the use of this method to study temporal variations of the water composition (Forsberg et al., 2006).

Another technique used in speciation studies is diffusive gradients in thin films (DGT). The DGT measures quantitatively labile species in aqueous solutions and can be used in complement to other techniques. It was developed by Zhang and Davison (1995) and has the advantage of pre-concentration of labile species in situ in aquatic systems. The labile fraction (LF) measured by this technique includes free metals and the species that can dissociate during the deployment time (Liu et al., 2013).

An important complexing agent in natural waters is the dissolved organic matter (DOM), especially the fraction of the humic substances (HS) (Tonello et al., 2007). HS make up 70-90\% of the NOM in some waters and are known to influence the distribution and behaviour of metals (Sargentini et al., 2001; Lenoble et al., 2015). Other colloids in natural waters include clays, natural iron and manganese oxides, which also have an important role in the mobilisation and bioavailability of metals and metalloids (Allard et al., 2004; Domingos et al., 2015).

Arsenic is a metalloid of environmental concern due to its toxicity when present in surface and ground waters. The toxicity of this metalloid is linked to its chemical form and especially its mobility is controlled by adsorption on mineral surfaces (Sundman et al., 2014; de Oliveira et al., 2015). DOM, for example, influences As speciation because it prevents the binding of As onto solid-phase surfaces. It consequently increases As mobility in aquatic systems (Kumaresan and Riyazuddin, 2001). This process of mobilisation is explained through the formation of ternary complexes between DOM, some di and trivalent cations (e.g. Fe and $\mathrm{Al}$ ) and As (Mikutta and Kretzschmar, 2011; Sharma et al., 2011).

The Quadrilátero Ferrífero $(\mathrm{QF})$ is an area located in the State of Minas Gerais (Brazil) that covers the upper Rio Doce River Basin and the Rio São Francisco River Basin. Minerals containing As appear in this region along with gold deposits. As a result, the concentration of As is higher at some points and mining contributed to make this toxic metalloid more available in the environment (Deschamps et al., 2002; Borba et al., 2003; Varcjao et al., 2011). The problem with As is widely known and very high As levels were reported even in the urine of children (Matschullat et al., 2000). However, the role and dynamics of the colloidal DOM and its influence on the distribution of As and metals as $\mathrm{Fe}$ and $\mathrm{Al}$ (due to their role in As speciation) has never been considered before for this region. This work aimed to study the distribution of As and $\mathrm{Fe}$ and $\mathrm{Al}$ within the total, dissolved, colloidal, free, labile and inert fractions of some rivers in the QF and to identify probable associations (complexation) between DOM and As. Multivariate analysis through Kohonen neural network (KNN) was used to investigate these associations and possible relationships among other variables. In addition, results for the free fraction of TUF experiments were compared with the labile fraction measured by DGT.

\section{Materials and methods}

Samples were taken from 12 points in the upper Rio Doce River Basin, east of the QF. The points were selected considering the accessibility, probable presence of As (from previous studies: Matschullat et al., 2000; Deschamps et al., 2002) and HS (brown coloured waters). The points located around the Rio do Carmo River and the Rio Conceição River are important for As studies due to the proximity to main gold mine districts as mentioned by Borba et al. (2003). Fig. 1 shows a map of the studied area and all sampling points. A satellite image of the sampling area is also available in the supplementary section (Fig. A.1, Appendix A). The rainy season samples were taken in February 2014 and the dry season samples in October 2014.

Physicochemical parameters were analysed in order to characterise the waters because these parameters may affect speciation and phase distribution of metals and metalloids in natural waters (Liu et al., 2013). Conductivity (COND), dissolved oxygen (DO), pH, oxidation reduction potential (ORP), temperature (TEMP) and turbidity (TU) were measured in situ using an Ultrameter II (Myron L Company) and a Hanna HI9829 (for DO) probe. Total alkalinity (ALK), chloride $\left(\mathrm{Cl}^{-}\right)$and sulphate $\left(\mathrm{SO}_{4}^{2-}\right)$ analyses were performed in the laboratory using potentiometric, argentometric and turbidimetric methods, respectively (Greenberg et al., 2005). 


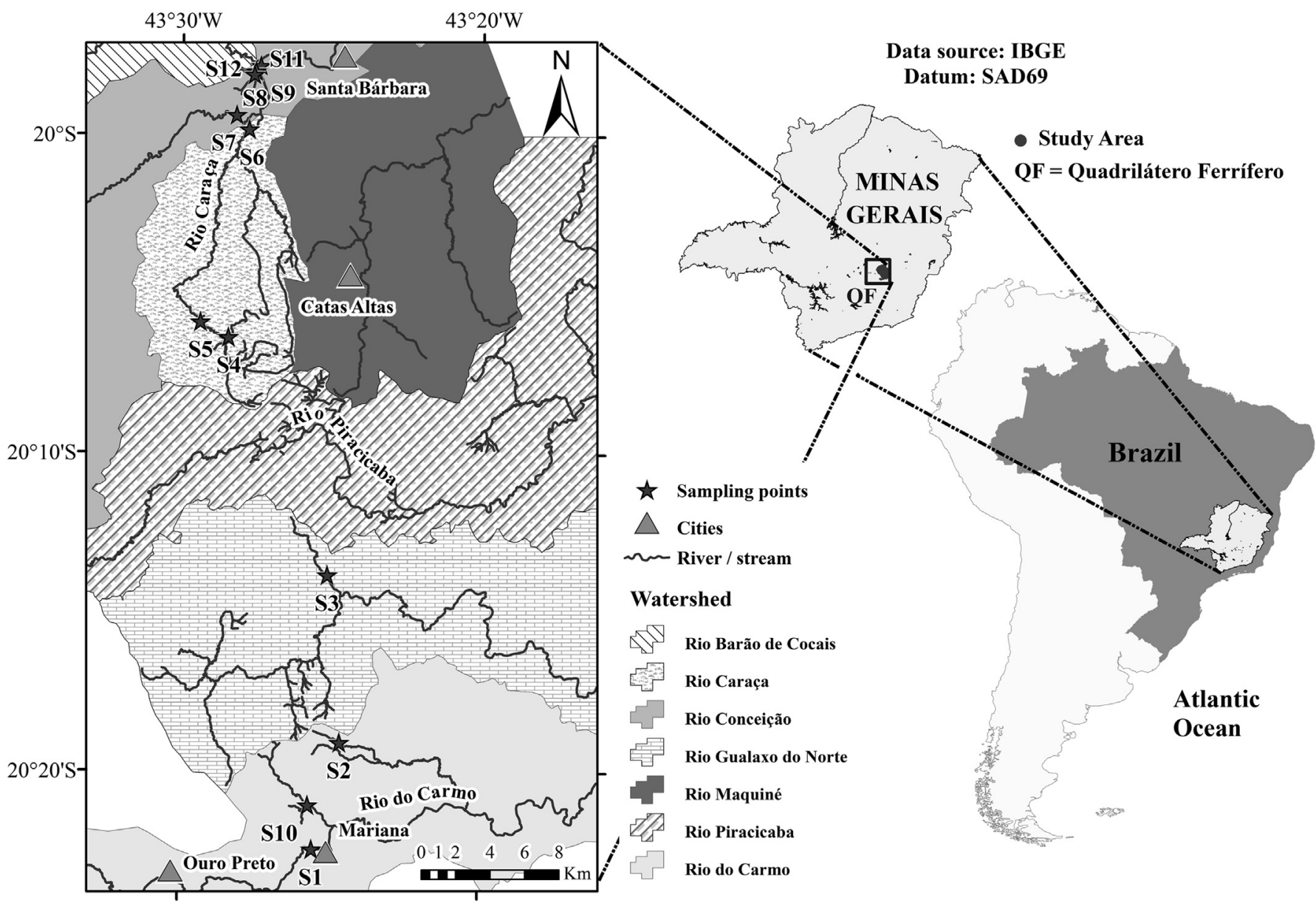

Fig. 1. Map showing the sampling points $(S)$ in the upper Rio Doce River basin in Quadrilátero Ferrífero, Minas Gerais, Brazil.

Around $2 \mathrm{~L}$ of water were collected at each point and stored in properly pre-cleaned plastic bottles (1 L each) in order to determine the fractions of metals and metalloids in rivers or streams. One of the bottles at each point was acidified with nitric acid $\left(\mathrm{HNO}_{3}\right)$ to $2 \%$ $\mathrm{v} / \mathrm{v}$ and reserved for the analysis of the total fraction (TF) of metals and metalloids. The other bottle was taken for the fractionation procedures and analyses of $\mathrm{ALK}^{-\mathrm{Cl}^{-}}$and $\mathrm{SO}_{4}^{2-}$. All samples were kept refrigerated until analysis.

Samples for the analysis of total organic carbon (TOC) and dissolved organic carbon (DOC) were stored in amber glass bottles $(60 \mathrm{~mL})$ previously cleaned. In addition, they were acidified with phosphoric acid $\left(\mathrm{H}_{3} \mathrm{PO}_{4}\right)$ and the samples for DOC analyses were immediately filtered through $0.45 \mu \mathrm{m}$ membranes.

The technique of DGT was used in order to determine the labile and inert species in some samples. In this way, five of the 12 sampling points were selected to deploy DGT devices. These points were chosen by considering probable higher amounts of As at the point S1 and in the Rio Conceição River Basin (Borba et al., 2003). The Rio Caraça River was richer in HS. There is an input of this material into the Rio Conceição River, which is richer in As. The five points were chosen to better understand the dynamics of As with input of organic material from Rio Caraça River. The amount of organic matter was considered at point S4 because of its brown coloured waters. Point S6 is located in the Rio Caraça River downstream to S4 and S6 and it was placed right before Rio Caraça River meets Rio Conceição River, where the points S7 and S9 were located. Point S7 is upstream of the confluence with the Rio Caraça River whereas point S9 is located downstream. These points were chosen to analyse the input, behaviour, and distribution of HS from the Rio Caraça River Basin in the presence of As in the Conceição River (Fig. A.2, Appendix A).

All DGT devices were assembled using piston-type devices purchased from DGT research (Lancaster, UK). A $0.45 \mu \mathrm{m}$ membrane, a diffusive gel and a binding gel composed each unit. The exposure area of all devices was $3.14 \mathrm{~cm}^{2}$. Chelex 100 gel was used as binding gel in order to measure the labile metals $\mathrm{Al}, \mathrm{Fe}$ and $\mathrm{Zn}$. The thickness of the diffuse gel (polyacrylamide hydrogel) was $0.88 \mathrm{~mm}$ and the thickness of the $0.45 \mu \mathrm{m}$ cellulose nitrate membranes was $0.13 \mathrm{~mm}$. Ferrihydrite gel was used as binding gel in order to measure labile As and P. Diffusion coefficients for all elements used in this work $\left(25^{\circ} \mathrm{C}\right.$ ) are shown in Table A.1 (Appendix A). All coefficients were corrected using the average temperature of the times of deployment and retrieving.

The concentration $\left(c_{\mathrm{e}}\right)$ of all elements were measured after elution of the binding gel. The Chelex-100 gels were eluted with $2 \mathrm{~mL}$ of $\mathrm{HNO}_{3}\left(1 \mathrm{~mol} \mathrm{~L}^{-1}\right)$. The ferrihydrite gels were eluted with $2 \mathrm{~mL}$ of concentrated hydrochloric acid $(\mathrm{HCl})$ and diluted after shaking for $24 \mathrm{~h}$. Then, the accumulated mass of the analyte (M) was calculated using Eq. (1), where $\mathrm{E}_{\mathrm{f}}$ is the elution factor, Ve is the volume of the eluent and $\mathrm{Vg}$ is the volume of the binding gel (Panther et al., 2008).

$\mathrm{M}=\mathrm{C}_{\mathrm{e}}\left(\mathrm{V}_{\mathrm{e}}-\mathrm{V}_{\mathrm{g}}\right) / \mathrm{E}_{\mathrm{f}}$

After determining $M$, the concentration of the analyte $\left(C_{a}\right)$ in the water of rivers and streams was calculated (Eq. (2)) using the 
thickness of the diffusive gel and cellulose nitrate filter $(\Delta g)$, the area exposed to the diffusive gel $(\mathrm{A})$, deployment time $(\mathrm{t})$ and the diffusive coefficient of the analyte in the diffusive gel (D) (Panther et al., 2008). All deployment times of the samples are available in Appendix A.

$C_{a}=\mathrm{M} \Delta \mathrm{g} / \mathrm{DtA}$

Samples for the analyses of the DF and the FF were filtered first using $0.45 \mu \mathrm{m}$ cellulose nitrate filters. Between 300 and $450 \mathrm{~mL}$ of the filtered sample were reserved for the analysis of the DF. About $150 \mathrm{~mL}$ of the pre-filtrated sample volume were ultrafiltrated using a TUF System. The ultrafiltration was undertaken using $1 \mathrm{kDa}$ regenerated cellulose ultrafiltration membranes (Millipore). Before ultrafiltration, the system was cleaned with sodium hydroxide $(\mathrm{NaOH})\left(0.1 \mathrm{~mol} \mathrm{~L}^{-1}\right)$ and $\mathrm{HCl}\left(<0.01 \mathrm{~mol} \mathrm{~L}^{-1}\right)$ solutions. After each step, the TUF system was rinsed abundantly with ultrapure water (18.2 M $\Omega$, Millipore).

To summarise, the elements analysed were separated in six fractions as shown in Table A.2 (Appendix A).

An acid digestion of the TF and the DF samples was performed based on the method 3005A of the US Environmental Protection Agency (USEPA). The acids ( $\mathrm{HCl}$ and $\mathrm{HNO}_{3}$ ) were previously purified using a sub-boiling system. In addition, the samples were preconcentrated along with this digestion procedure. A concentration factor $(\mathrm{CF})$ of six was used for the TF and DF samples. All analyses were performed in triplicate. The digestion with pre-concentration was validated using spike recovery tests. The validation procedure and results are shown in Appendix A (section A.6). The FF samples were acidified with $\mathrm{HNO}_{3}$ (until $2 \%$ ) and pre-concentrated $(\mathrm{CF}=4)$.

All metals and $P$ were determined using an Inductively Coupled Plasma - Atomic Emission Spectrometry (ICP-OES) instrument (Agilent Technologies 700 Series). As was determined in a VARIAN AA240Z graphite furnace atomic absorption spectrometer (GFAAS). Fig. A.3 (Appendix A) shows the main points in the methodology. All elements were determined from mineralised samples.

For the analyses of As in the presence of DOC by GFAAS it was necessary to perform a sequence of optimisation tests showed in Appendix A (supplementary material). The limit of detection (LOD) and the limit of quantification (LOQ) of all elements analysed (both ICP-OES and GFAAS) are also shown in this session.

The data were analysed using the KNN (self-organising maps (SOM)). The software MatLab 2015b (MathWorks, Natick, MA) and the SOM toolbox (public domain) were used to perform this multivariate exploratory analysis (Alhoniemi et al., 2000). More information about this technique can be found in previous works (Garcia et al., 2007; Gontijo et al., 2014).

Two kinds of analyses were performed. The first one aimed to investigate the physicochemical parameters and the fractions of the elements $\mathrm{Al}$, As and $\mathrm{Fe}$ at all 12 points (just UF results). The total fraction of other elements was included to check probable influence of them in the distribution of $\mathrm{Al}, \mathrm{As}$ and $\mathrm{Fe}$. The second analysis was performed just in the points where the DGT were deployed (UF and DGT results). It included all the fractions of metals obtained via filtration and ultrafiltration and the labile fraction.

Before processing the results, the datasets were autoscaled along all variables in order to normalise the variance of the samples and redefine the averages as zero. This step is important because the KNN uses the Euclidian metric to calculate the distances between the vectors. Then, if one variable has higher values than others, it will dominate the map organisation (because the impact of the measurements of the distances between vectors). Nevertheless, it is desirable that all the variables have the same level of importance what makes this step mandatory (Silva et al., 2008).

The structure of each unit (neuron) in the KNN was hexagonal and the map shape was planar. Several architectures (at least 5 in the interval from $2 \times 2$ to $9 \times 9$ ) were tested. Afterwards, the architecture that had the better distribution (more informative) was chosen. This choice is related to the discrimination of the samples. Samples in the same neuron are considered very similar according to the variables and samples evaluated. Samples in neighbour or closer neurons can also be considered similar. Consequently, all the samples will stay together in maps with few units and will stay very separated in too big maps. It makes important to find the best distribution (Kowalski et al., 2013).

Because some elements ( $\mathrm{Al}, \mathrm{As}, \mathrm{Fe}$ and $\mathrm{P}$ ) exhibit mostly concentrations below LOQ but above LOD within some fractions, KNN was also used to check if these data can be used for multivariate analyses. This test was carried out with results from both, samples of the ultrafiltration experiments and from the DGT (labile + TUF fractions included). All results from these tests are showed in Appendix A.

\section{Results and discussion}

Results of physicochemical, anion and phosphorous analyses are shown in Table A.6 (Appendix A). Most of the $\mathrm{pH}$ values were in the neutral range around 7. More acidic waters were found at points S2, S4 and S5, especially during the rainy season. Higher ALK was observed at points $\mathrm{S} 1$ and $\mathrm{S} 12$. The point $\mathrm{S} 1$ also reached one of the highest values for $\mathrm{SO}_{4}^{2-}, \mathrm{Cl}^{-}$and $\mathrm{P}$ total, probably linked to a sewage discharge upstream. Water with more oxic conditions (higher ORP) was found at point S4. The points S2 and S12 (dry season) exhibit water with more reduced characteristics. Further analyses of the data will be given along with the multivariate analysis.

The results of the total and dissolved organic carbon are shown in Fig. 2. Most of the total carbon in the samples is dissolved and therefore more mobile and bioavailable. However, some points (S2, S3, S10, and S12) exhibit a higher particulate fraction of TOC. Most of the waters had concentrations below $6 \mathrm{mg} \mathrm{L}^{-1}$ of TOC. Sampling point S2 showed higher concentration of DOC in the dry season and sample point S4 had higher carbon concentration in the rainy season (DOC and TOC). Along with lower $\mathrm{pH}$ at these points, the DOC here probably is linked to humic and fulvic acids.

The architectures of the KNN that showed the best distribution of the samples was $7 \times 7$ and $4 \times 4$ for the dataset of UF and DGT samples, respectively.

The final maps of Kohonen using the LOD dataset for the UF (left) and UF + DGT (right) samples are shown in Fig. 3. The groups of similar samples were circled and numbered. The neurons with samples in the dry and rainy seasons were highlighted.

The maps of variables studied are available in the supplementary material (Fig. A.7, UF dataset, and Fig. A.8, UF + DGT dataset) and help to identify the most impactful variable(s) for each sample and the possible relationships among them. From Fig. 3a, samples could be separated in nine distinct groups. The analyses were performed comparing the samples in this map with their corresponding position in the map of variables (Fig. A.7). From Fig. 3b samples could be separated in three distinct groups. The analyses were performed comparing the samples in this map with their corresponding position in the map of variables (Fig. A.8). Table 1 shows the characteristics of each of these groups of samples.

There was no clear separation observed between samples collected in the dry and in the rainy seasons (e.g. S3R, S3D, S4R, S4D, S5R and S5D belong to group I, samples S10D and S10R to group IV in Fig. 3a; see also Table 1). Therefore, the seasonality did not influence most of the samples. Sampling point S2 was an exception and a greater difference was observed between the samples collected in the dry and the rainy season. This difference can be attributed especially to the higher levels of organic matter and Fe. 


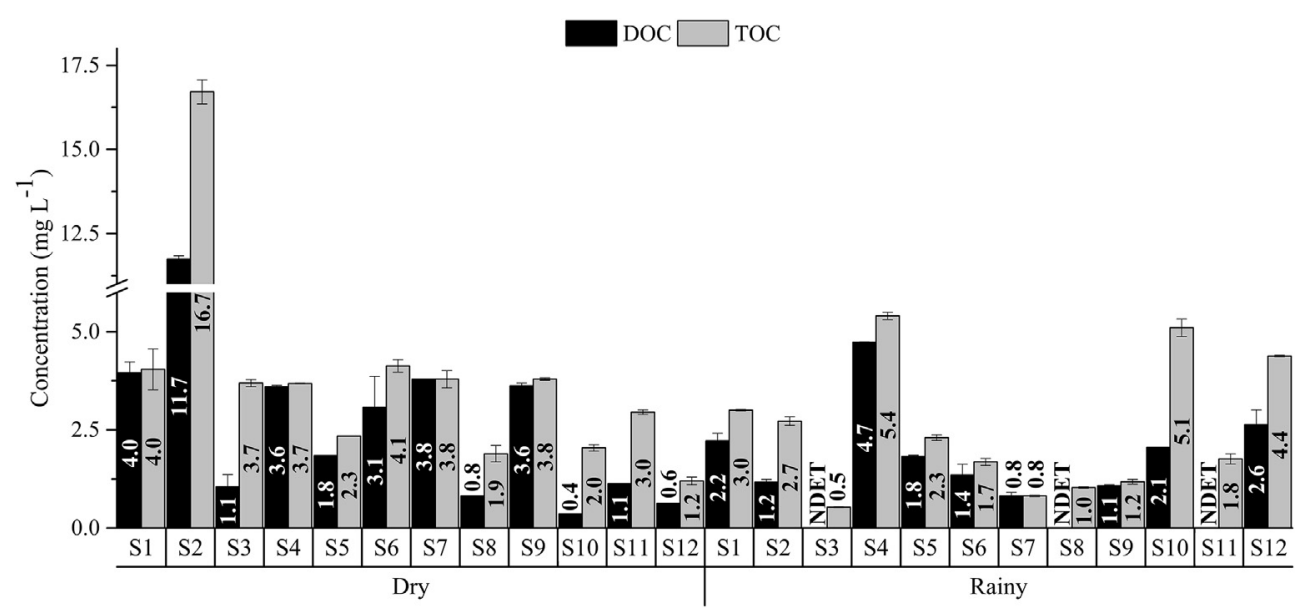

Fig. 2. Results of dissolved organic carbon and total organic carbon in samples (dry and rainy seasons) collected in the Quadrilátero Ferrífero (Brazil).

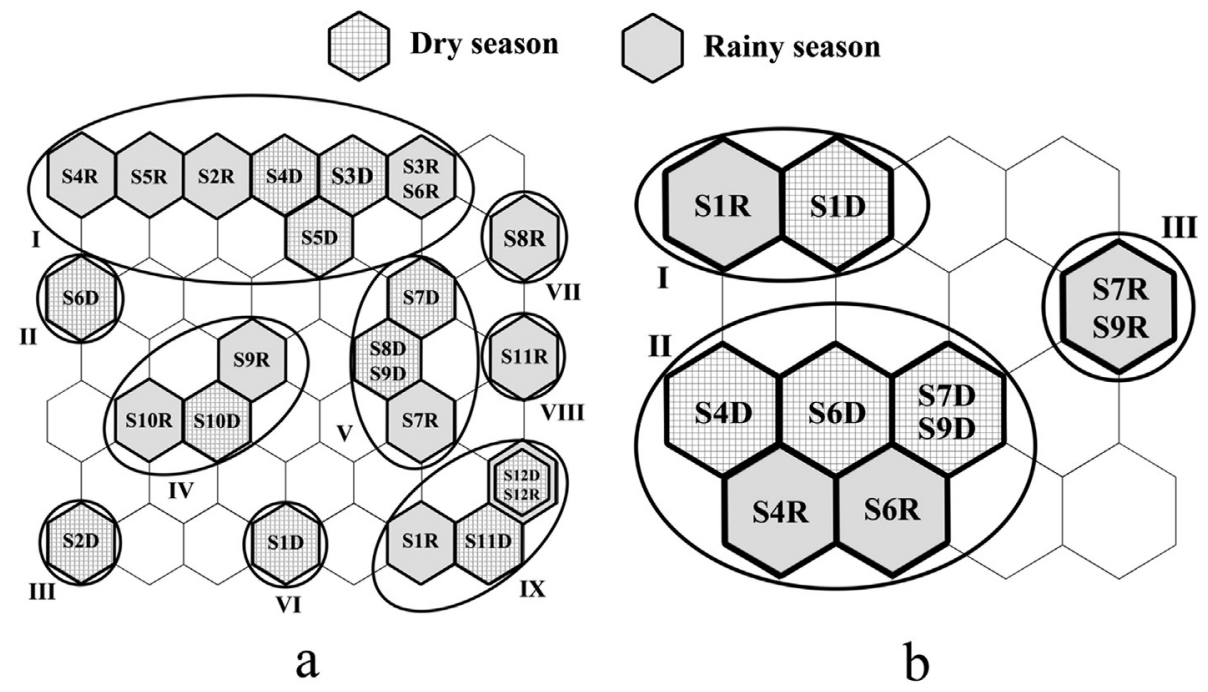

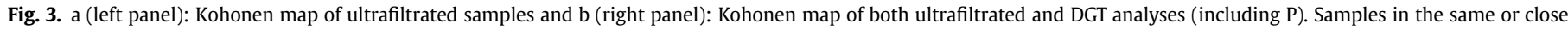

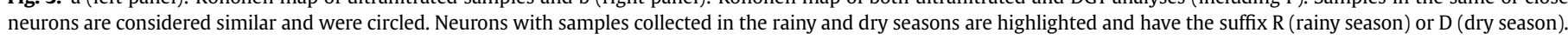

Table 1

Characteristics of each group of samples (ultrafiltrated and ultrafiltrated + DGT analyses) from Kohonen neural network.

\begin{tabular}{|c|c|c|}
\hline $\begin{array}{l}\text { Group- } \\
\text { No }\end{array}$ & Samples & Characteristics \\
\hline \multicolumn{3}{|c|}{ Ultrafiltrated samples } \\
\hline I & $\begin{array}{l}\text { S2R, S6R and S3, S4 and S5 (both } \\
\text { seasons) }\end{array}$ & Lower $\mathrm{pH}$ and higher ORP \\
\hline II & S6D & Similar to group I but has higher levels of AlT and ZnT \\
\hline III & S2D & Low pH value, high TU value, higher levels of TOC, DOC and Fe (all fractions) and lower levels of As (all fractions) \\
\hline IV & S9R and S10 (both seasons) & Higher levels of DO, AlD, AlC, AsT, AsD, AsPtc and MnD \\
\hline $\mathrm{V}$ & S7 (both seasons), S8D and S9D & Higher amounts of CaT, SrT and SrD \\
\hline VI & S1D & Higher COND and higher amounts of TDS, KT, KD, KPtc, KC, MnT, MnPtc and AsD \\
\hline VII & S8R & Higher DO value \\
\hline VIII & S11R & Higher levels of SrT and SrD \\
\hline IX & S1R, S11D and S12 (both seasons) & Higher levels of ALK, CaT, MgT and SrT \\
\hline \multicolumn{3}{|c|}{ Ultrafiltrated + DGT samples } \\
\hline I & S1 (both seasons) & Higher levels of COND, TDS, ALK, AsT, MgT, MnT, PT, AsD, KD, AsPtc, KPtc, KPtc, KC, AsL and PL \\
\hline II & S4, S6 (both seasons), S7D and S9D & $\begin{array}{l}\text { Lower pH values, TDS, lower concentrations of CaT, KT, MgT, but higher ORP values and higher concentrations of AIC, AsC, } \\
\text { AlL and FeL }\end{array}$ \\
\hline III & S7R and S9R & Higher levels of pH, T, MnC and AlL \\
\hline
\end{tabular}

The conditions at S2 were also different between the two seasons. In the rainy season the stream was flowing with higher discharge whereas in the dry season flow was extremely low. In addition, the similarity proved to be even higher (samples in the same group) in 
Fig. 3b, which considers the UF + DGT analyses.

More complexed $\mathrm{Fe}(\mathrm{FeC})$ was detected in the samples S7R and S9R (group III, Fig. 3b), but less DOC (observing these variables in Fig. A.8). In addition, the amount of total Fe and $\mathrm{pH}$ in these samples was also higher than other samples in Fig. $3 \mathrm{~b}$. This behaviour can be explained by $\mathrm{pH}$ and $\mathrm{Fe}$ concentration, which influence the $\mathrm{Fe}$ speciation (Sundman et al., 2014). Higher pH values, for instance, can decrease the amount of Fe complexed with organic matter and induce the precipitation of this metal in natural waters (Allard et al., 2004; Sundman et al., 2014). It was observed in Fig. A.8 (supplementary material) that the sampling points with more complexed Fe (S7R and S9R) had less labile As. A possible explanation is the formation of ternary complexes between organic matter, Fe and As.

Concerning other elements it was found that sampling points with more Ca (S1D, S7D, S9D, S1R, S7R and S9R) showed more Mg and $\mathrm{Sr}$ amounts, probably due to lithological reasons (Gontijo et al., 2014). The behaviour of Al was similar to the Fe. Less DOC was found at that sampling points where more labile $\mathrm{Zn}$ was found.

The distribution of the fractions for $\mathrm{Al}$, As and $\mathrm{Fe}$ in all samples is shown in Fig. 4. For some samples it was not possible to determine the distribution of these metals because the concentrations in the total or dissolved fraction were below the LOD. If only the concentration within the free fraction was below the LOD, it was displayed as dissolved fraction since then it was not possible to calculate the percentage of the colloidal fraction.

In general, most of the Fe occurred in the particulate fraction (between 60 and 100\% for most samples). The colloidal Fe was the second major fraction (between 5 and 90\% within the samples), whereby this metal may appear as Fe-oxyhydroxides, clays or organic-complexed colloids (Vasyukova et al., 2010; Liu et al., 2013). The FF was of minor importance for Fe within the investigated samples (less than $10 \%$ of the total Fe). The fact that Fe binds strongly with colloidal HS (principal complexing agent in the colloidal fraction) can explain the distribution among the free and colloidal fractions (Liu et al., 2013). The same behaviour was observed for $\mathrm{Al}$, probably also bound to colloidal organic matter (Liu et al., 2013).

The behaviour of As was different as it appeared more abundant within the FF because As is not able to bind significantly with HS. However, the samples S9R, S11R, S8D and S9D had a higher amount of As within the colloidal fraction (20-32\%). The formation of ternary complexes by the input of organic material from the brown coloured water of the point S4 can explain this higher percentage of colloidal As at the points S8 and S9. The amount of dissolved As was low (below $1 \mu \mathrm{g} \mathrm{L}^{-1}$ ) in the samples S2D, S4D, S5D, S6D and S7D and therefore the concentration within the free fraction was not detectable. Consequently, it was not possible to calculate the amount of the colloidal or free fractions in these samples.

Considering the seasonality, the concentration of Fe in the dry season was much higher when compared to rainy season (14.7 $\mathrm{mg} \mathrm{L}^{-1}$ and $360 \mu \mathrm{g} \mathrm{L}^{-1}$, respectively). It was probably linked to the lithology and occurred nearly exclusively in the particulate fraction, which is then simply diluted in the rainy season. Similar behaviour was observed for Al. This effect was most pronounced in sample S2, which had only $9 \%$ of particulate $\mathrm{Al}$ and $6 \%$ of particulate Fe during the rainy season. In the dry season, the amount of these

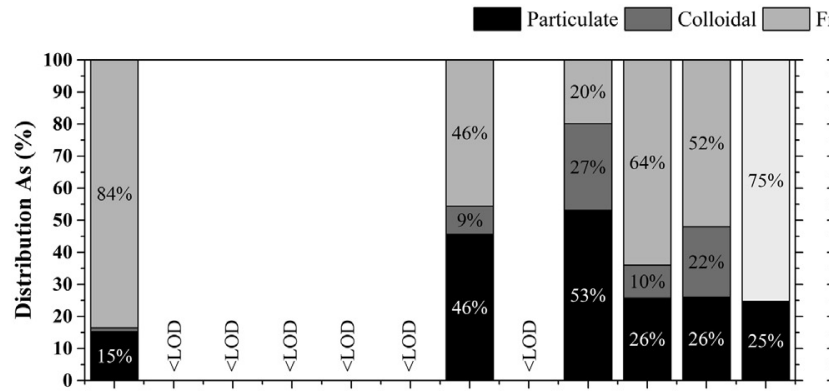

Free $\square$ Dissolved (= colloidal + free $)$
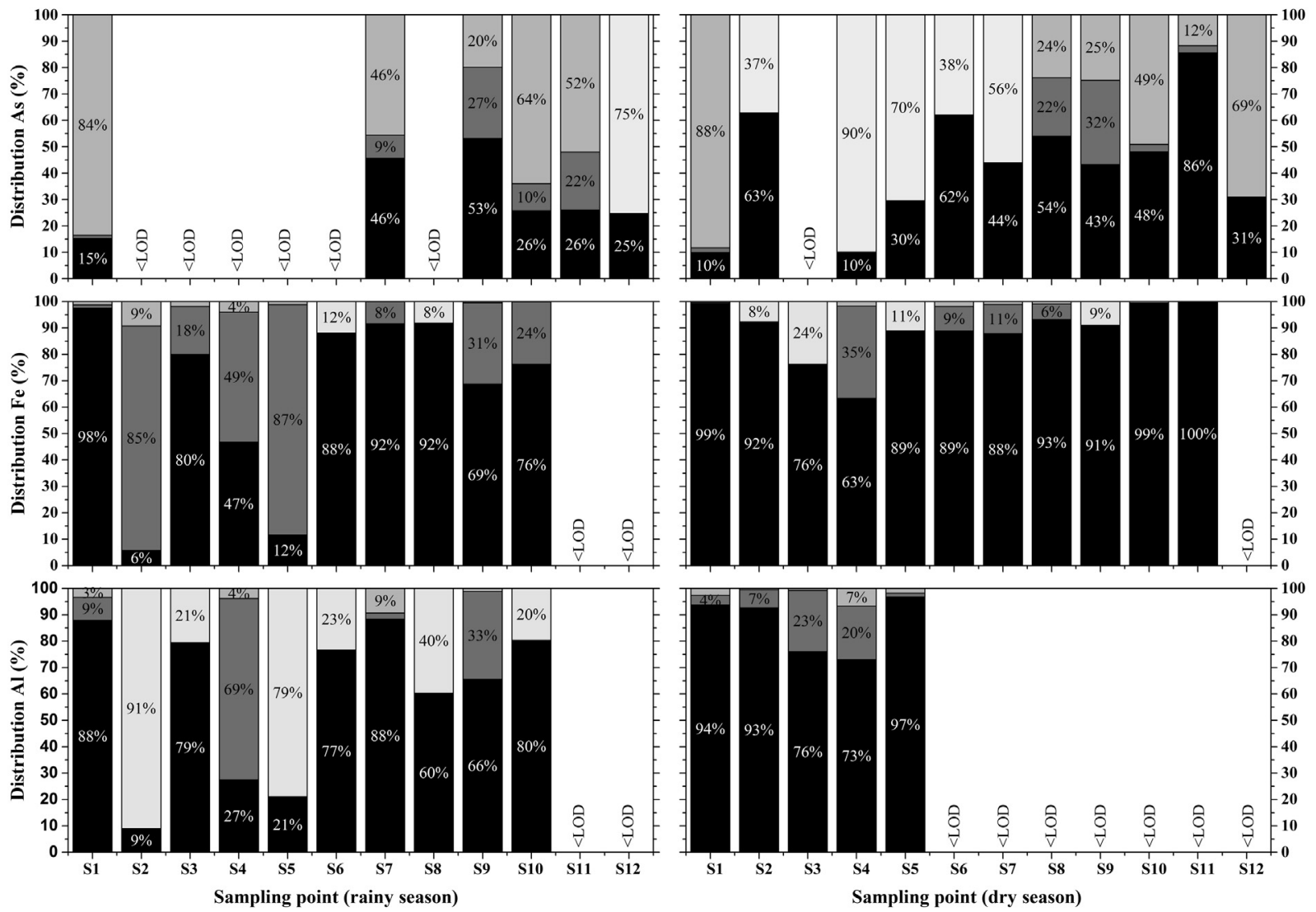

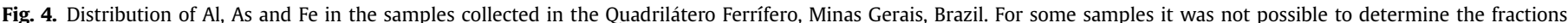

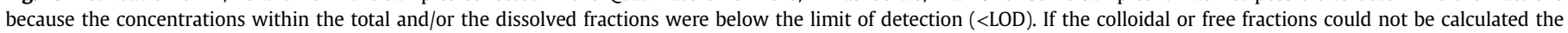
values are given as dissolved fraction. 
metals in the particulate fraction increased about 10 times (93\% and 92\% for $\mathrm{Al}$ and $\mathrm{Fe}$, respectively). In addition, it is known that at higher Fe concentrations and higher $\mathrm{pH}$ values Fe tends to precipitate as Fe(III) hydr(oxides) (Kaeding, 1973; Sundman et al., 2014). This distribution behaviour can also explain the differences between dry and rainy seasons detected in KNN (between samples S2D and S2R) (Fig. 3a).

The concentrations of dissolved, free (from TUF) and labile (from DGT) Al, As and Fe for the samples taken by the deployment of DGT are shown in Fig. 5.

An important definition that will be used in this work is the potential bioavailability of an element as that part which was determined as the labile species fixed by the binding gels of the DGT. Because different organisms have different uptake mechanisms, some metal or metalloid species will be available only if the uptake rate by these organisms is high enough to produce a gradient in the medium. Consequently, some complexed species defined as labile may dissociate and can be incorporated by the organism (Zhang and Davison, 2015).

Considering these concepts, Fig. 5 shows that most of the dissolved As is labile in the samples analysed. Therefore, it can be concluded that As is potentially bioavailable to the organisms that live and consume this water. This is especially important at sampling point $\mathrm{S} 1$ where the total concentration of As is more than two times as recommended for human consumption $\left(10 \mu \mathrm{g} \mathrm{L}^{-1}\right)$ by WHO and by the Brazilian legislation for natural waters (BRASIL, 2005). On the other hand, most of the $\mathrm{Al}$ and $\mathrm{Fe}$ is in the inert fraction, predominately complexed by HS and therefore less bioavailable.

Differences between the ultrafiltration and DGT results can be related to either chemical processes or methodological distinctions. Concerning the chemical processes, part of the colloidal fraction of an element can be labile during the deployment time of DGT. Consequently, this element will show higher concentrations in the labile fraction by DGT measurements than in the free fraction from the ultrafiltration $<1 \mathrm{kDa}$ (e.g. Fe in sample S1D had higher amount
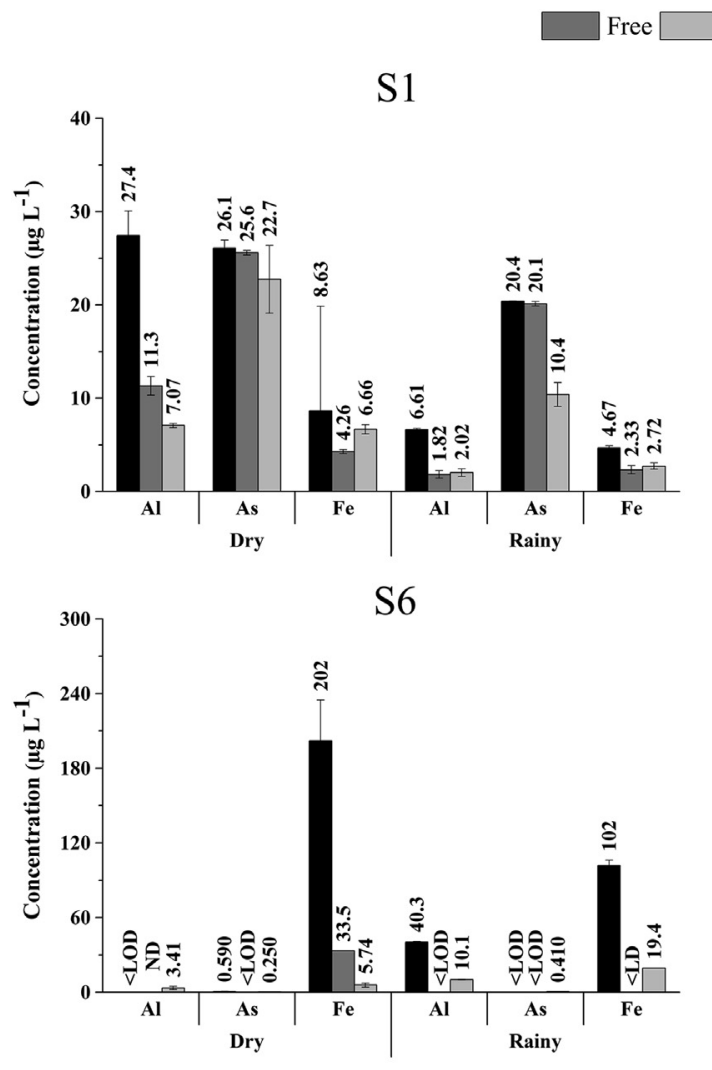

Labile Dissolved
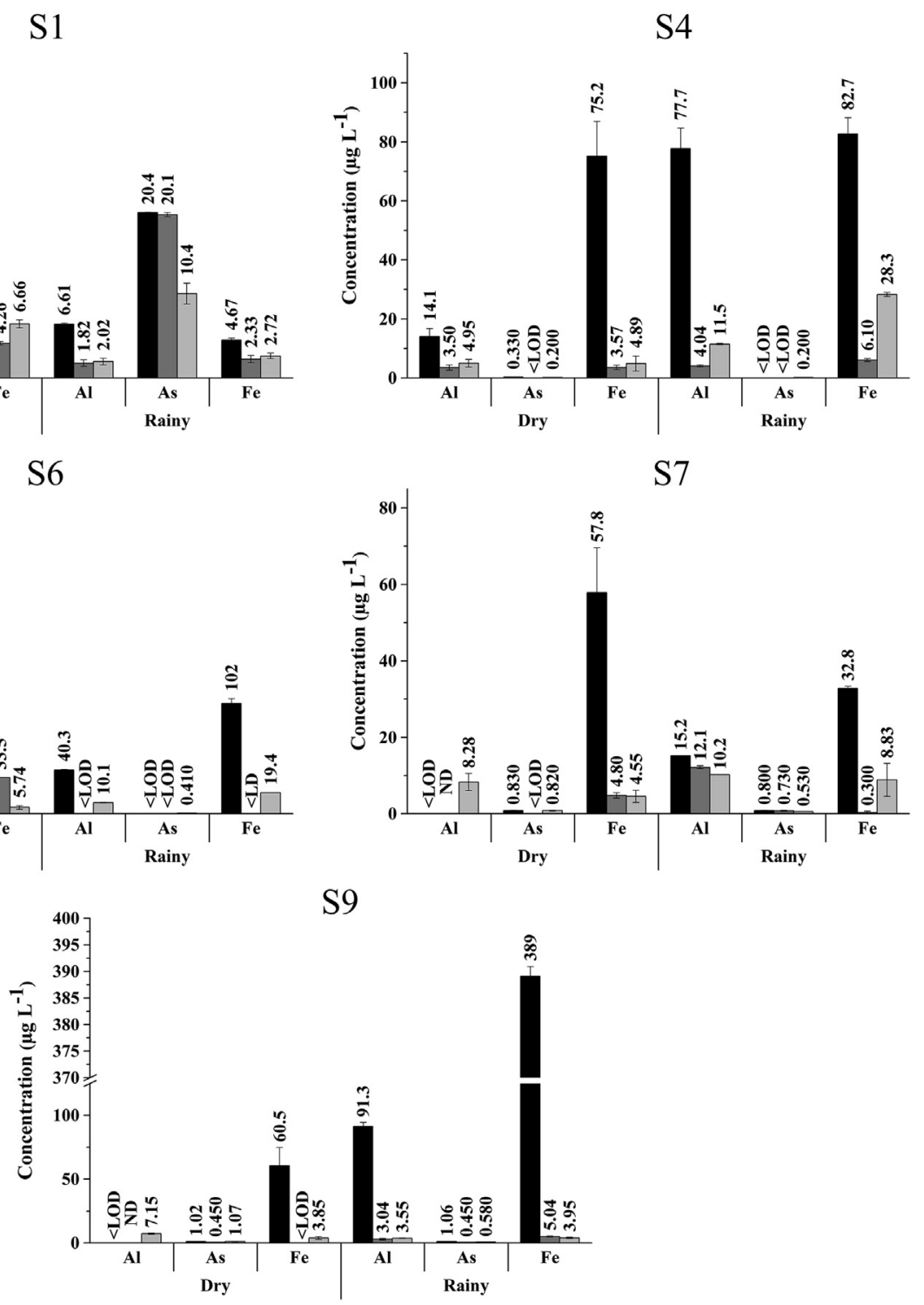

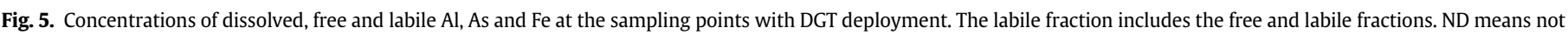
determined. 
in the labile fraction than in the free fraction, Fig. 5). The same observation is valid for $\mathrm{Fe}$ and $\mathrm{Al}$ in sample S4R. About methodological distinctions, while UF results refer to a single moment of sampling, DGT accumulates the labile species over a long and continuous time period. This might explain the differences between very high concentrations of elements in the free fraction compared to its significantly lower concentration in the labile fraction as observed for As in sample S1R and for Fe in sample S6D (Fig. 5). If the high concentrations of these elements occurred not all the time of DGT deployment the concentration in the binding gel will be balanced to the average of the deployment time.

On the other hand, DGT technique has some pre-concentration advantages when compared to ultrafiltration, especially for metals found in very low amounts (Zhang and Davison, 1995). This might explain why for some samples Fe was detected in DGT analyses but not in the UF analyses (e.g. S9R). On the other hand, changes in the speciation of $\mathrm{Al}$, As and $\mathrm{Fe}$ before ultrafiltration analyses would also explain these differences (Tonello et al., 2011).

\section{Conclusions}

In general, most of the $\mathrm{Al}$ and $\mathrm{Fe}$ occurred in the particulate fraction (less mobile) at the sampling points analysed in the upper Rio Doce River Basin. The free fraction was more representative for As but at some sampling points the colloidal fraction of As was higher (up to 30\%). Multivariate exploratory analysis showed that sampling points with more complexed Fe had less labile As. In general, samples taken in the dry and rainy seasons exhibit a similar behaviour (seasonality was not a strong factor) considering all variables measured using KNN. However, it was detected some differences in the distribution of the elements As, Al, and Fe among the four fractions (particulate, dissolved, colloidal, and free). Influence of other elements for the speciation of As was not detected in the multivariate analyses.

Most of the dissolved As appeared in the labile fraction of DGT and can therefore be attributed to be more bioavailable. This is especially important in areas where As has higher concentrations and may be dangerous for organisms. Lower amounts of $\mathrm{Al}$ and $\mathrm{Fe}$ in the labile fraction are explained by the complexation with organic matter. Concentration differences between the free and labile species are probably linked to the lability of colloidal species and the period of measurement (DGT covers a greater period whereas ultrafiltration represent only a single moment). The UF experiments were not performed in situ and consequently part of the differences can also be explained by changes in speciation during transportation of samples from the field to the laboratory. In this way, DGT provided a more accurate value of the bioavailability of the elements analysed. Nevertheless, as demonstrated by our work, both techniques can be complementary, since UF provides information about free species and DGT provide information about labile species (which include free species).

\section{Acknowledgements}

We would like to thank the Fundação de Amparo à Pesquisa do Estado de São Paulo (FAPESP) proc. 2012/17727-8, the Coordenação de Aperfeiçoamento de Pessoal de Nível Superior (CAPES) proc. BEX10452/14-1, Conselho Nacional de Desenvolvimento Científico e Tecnológico (CNPq) proc. 400572/2013-3 and the Deutscher Akademischer Austauschdienst (DAAD) for the scholarship and financial support of E.S. We acknowledge the help of the Programa de Pós-Graduação em Engenharia Ambiental (PROAMB) from the Universidade Federal de Ouro Preto (UFOP) and all the people that supported the field trips.

\section{Appendix A. Supplementary data}

Supplementary data related to this article can be found at http:// dx.doi.org/10.1016/j.chemosphere.2016.08.107.

\section{References}

Alhoniemi, E., Himberg, J., Parhankangas, J., Vesanto, J., 2000. SOM Toolbox.

Allard, T., Menguy, N., Salomon, J., Calligaro, T., Weber, T., Calas, G., Benedetti, M.F., 2004. Revealing forms of iron in river-borne material from major tropical rivers of the Amazon Basin (Brazil)1. Geochim. Cosmochim. Acta 68, 3079-3094.

Aung, N.N., Nakajima, F., Furumai, H., 2008. Trace metal speciation during dry and wet weather flows in the Tama River, Japan, by using diffusive gradients in thin films (DGT). J. Environ. Monit. 10, 219-230.

Borba, R.P., Figueiredo, B.R., Matschullat, J., 2003. Geochemical distribution of arsenic in waters, sediments and weathered gold mineralized rocks from Iron Quadrangle. Braz. Environ. Geol. 44, 39-52.

BRASIL, 2005. Resolução No 357, de 17 de março de 2005. CONAMA.

Buffle, J., 1991. Complexation Reactions in Aquatic Systems: an Analytical Approach, Ellis Horwood Ltd.

de Oliveira, L.K., Melo, C.A., Goveia, D. Lobo, F.A., Armienta Hernández, M.A. Fraceto, L.F., Rosa, A.H., 2015. Adsorption/desorption of arsenic by tropical peat: influence of organic matter, iron and aluminium. Environ. Technol. 36, 149-159.

Deschamps, E., Ciminelli, V.T., Lange, F., Matschullat, J., Raue, B., Schmidt, H., 2002. Soil and sediment geochemistry of the iron quadrangle, Brazil the case of arsenic. J. Soils Sediments 2, 216-222.

Domingos, R.F., Gelabert, A., Carreira, S., Cordeiro, A., Sivry, Y., Benedetti, M.F., 2015. Metals in the aquatic environment-interactions and implications for the speciation and bioavailability: a critical overview. Aquat. Geochem 21, 231-257.

Forsberg, J., Dahlqvist, R., Gelting-Nystrom, J., Ingri, J., 2006. Trace metal speciation in brackish water using diffusive gradients in thin films and ultrafiltration: comparison of techniques. Environ. Sci. Technol. 40, 3901-3905.

Garcia, J.S., Da Silva, G.A., Arruda, M.A.Z., Poppi, R.J., 2007. Application of Kohonen neural network to exploratory analyses of synchroton radiation X-ray fluorescence measurements of sunflower metalloproteins. X-Ray Spectrom. 36, $122-129$.

Gontijo, E.S.J., Oliveira, F.S.D., Fernandes, M.L., da Silva, G.A., Roeser, H.M.P., Friese, K., 2014. Application of a multivariate exploratory analysis technique in the study of dissolved organic matter and metal ions in waters from the eastern Quadrilatero Ferrifero, Brazil. J. Braz. Chem. Soc. 25, 208-218.

Greenberg, A.E., Cleresci, L.S., Eaton, A.D. (Eds.), 2005. Standard Methods for the Examination of Water and Wastewater. American Public Health Association, American Water Works Association and Water Environment Federation, Washington, D.C.

Kaeding, J., 1973. W. Stumm und J. J. Morgan: Aquatic Chemistry an Introduction Emphasizing Chemical Equilibria in Natural Waters. New York, London, Sydney, Toronto, Wiley-Interscience, 1970, 583 S., zahlr. Abb. und Tab. Acta hydrochimica et hydrobiologica 1, 117-117.

Kowalski, C.H., da Silva, G.A., Godoy, H.T., Poppi, R.J., Augusto, F., 2013. Application of Kohonen neural network for evaluation of the contamination of Brazilian breast milk with polychlorinated biphenyls. Talanta 116, 315-321.

Kumaresan, M., Riyazuddin, P., 2001. Overview of speciation chemistry of arsenic. Curr. Sci. 80, 837-846.

Lenoble, V., Dang, D.H., Loustau Cazalet, M., Mounier, S., Pfeifer, H.R., Garnier, C., 2015. Evaluation and modelling of dissolved organic matter reactivity toward AsIII and AsV - implication in environmental arsenic speciation. Talanta 134, 530-537.

Liu, R., Lead, J.R., Zhang, H., 2013. Combining cross flow ultrafiltration and diffusion gradients in thin-films approaches to determine trace metal speciation in freshwaters. Geochim. Cosmochim. Acta 109, 14-26.

Matschullat, J., Borba, R.P., Deschamps, E., Figueiredo, B.R., Gabrio, T., Schwenk, M., 2000. Human and environmental contamination in the iron quadrangle. Braz. Appl. Geochem 15, 181-190.

Mikutta, C., Kretzschmar, R., 2011. Spectroscopic evidence for ternary complex formation between arsenate and ferric iron complexes of humic substances. Environ. Sci. Technol. 45, 9550-9557.

Panther, J.G., Stillwell, K.P., Powell, K.J., Downard, A.J., 2008. Development and application of the diffusive gradients in thin films technique for the measurement of total dissolved inorganic arsenic in waters. Anal. Chim. Acta 622, 133-142.

Romão, L.P.C., Castro, G.R., Rosa, A.H., Rocha, J.C., Padilha, P.M., Silva, H.C., 2003. Tangential-flow ultrafiltration: a versatile methodology for determination of complexation parameters in refractory organic matter from Brazilian water and soil samples. Anal. Bioanal. Chem. 375, 1097-1100.

Sargentini, E., Rocha, J.C., Rosa, A.H., Zara, L.F., dos Santos, A., 2001. Aquatic humic substances: molecular size fractionation and characterization of inner rearrangements after metal ions complexation. Quimica Nova 24, 339-344.

Sharma, P., Rolle, M., Kocar, B., Fendorf, S., Kappler, A., 2011. Influence of natural organic matter on as transport and retention. Environ. Sci. Technol. 45, $546-553$.

Silva, G.A.d., Augusto, F., Poppi, R.J., 2008. Exploratory analysis of the volatile profile of beers by HS-SPME-GC. Food Chem. 111, 1057-1063.

Song, Y.T., Swedlund, P.J., Singhal, N., Swift, S., 2009. Cadmium(II) speciation in 
complex aquatic systems: a study with ferrihydrite, bacteria, and an organic ligand. Environ. Sci. Technol. 43, 7430-7436.

Sundman, A., Karlsson, T., Sjoberg, S., Persson, P., 2014. Complexation and precipitation reactions in the ternary $\mathrm{As}(\mathrm{V})-\mathrm{Fe}(\mathrm{III})-\mathrm{OM}$ (organic matter) system. Geochim. Cosmochim. Acta 145, 297-314.

Tonello, P., Goveia, D., Rosa, A., Fraceto, L., Menegario, A., 2011. Determination of labile inorganic and organic species of $\mathrm{Al}$ and $\mathrm{Cu}$ in river waters using the diffusive gradients in thin films technique. Anal. Bioanal. Chem. 399, 2563-2570.

Tonello, P.S., Rosa, A.H., Abreu Jr., C.H., Menegário, A.A., 2007. Use of diffusive gradients in thin films and tangential flow ultrafiltration for fractionation of Al(III) and $\mathrm{Cu}(\mathrm{II})$ in organic-rich river waters. Anal. Chim. Acta 598, 162-168.

USEPA, Method 3005A. Acid Digestion of Waters for Total Recoverable or Dissolved Metals for Analysis by FLAA or ICP Spectroscopy.

Varcjao, E.V.V., Bellato, C.R., Fontes, M.P.F., Mello, J.W.V., 2011. Arsenic and trace metals in river water and sediments from the southeast portion of the Iron Quadrangle. Braz. Environ. Monit. Assess. 172, 631-642.

Vasyukova, E.V., Pokrovsky, O.S., Viers, J., Oliva, P., Dupré, B., Martin, F. Candaudap, F., 2010. Trace elements in organic- and iron-rich surficial fluids of the boreal zone: assessing colloidal forms via dialysis and ultrafiltration. Geochim. Cosmochim. Acta 74, 449-468.

Wen, L.-S., Santschi, P.H., Gill, G.A., Paternostro, C.L., Lehman, R.D., 1997. Colloidal and particulate silver in river and estuarine waters of Texas. Environ. Sci. Technol. 31, 723-731.

Zhang, H., Davison, W., 1995. Performance characteristics of diffusion gradients in thin films for the in situ measurement of trace metals in aqueous solution. Anal. Chem. 67, 3391-3400.

Zhang, H., Davison, W., 2015. Use of diffusive gradients in thin-films for studies of chemical speciation and bioavailability. Environ. Chem. 12, 85-101. 